\title{
Towards an effective control programme of soil-transmitted helminth infections among Orang Asli in rural Malaysia. Part 1: Prevalence and associated key factors
}

Nabil A Nasr ${ }^{1}$, Hesham M Al-Mekhlafi ${ }^{1,4^{*}}$, Abdulhamid Ahmed ${ }^{2}$, Muhammad Aidil Roslan $^{1}$ and Awang Bulgiba ${ }^{3}$

\begin{abstract}
Background: Despite the continuous efforts to improve the quality of life of Orang Asli (Aborigines) communities, these communities are still plagued with a wide range of health problems including parasitic infections. The first part of this study aimed at determining the prevalence of soil-transmitted helminth (STH) infections and identifying their associated factors among rural Orang Asli children.
\end{abstract}

Methods: A cross-sectional study was carried out among 484 Orang Asli children aged $\leq 15$ years (235 females and 249 males) belonging to 215 households from 13 villages in Lipis district, Pahang, Malaysia. Faecal samples were collected and examined by using formalin-ether sedimentation, Kato Katz and Harada Mori techniques.

Demographic, socioeconomic, environmental and behavioural information were collected by using a pre-tested questionnaire.

Results: Overall, $78.1 \%$ of the children were found to be infected with one or more STH species. The prevalence of trichuriasis, ascariasis and hookworm infections were $71.7 \%, 37.4 \%$ and $17.6 \%$, respectively. Almost all, three quarters and one fifth of trichuriasis, ascariasis and hookworm infections, respectively, were of moderate-to-heavy intensities. Multiple logistic regression analysis showed that age of $\geq 6$ years (school-age), using unsafe water supply as a source for drinking water, absence of a toilet in the house, large family size ( $\geq 7$ members), not washing hands before eating, and not washing hands after defecation were the key factors significantly associated with STH among these children.

Conclusion: This study reveals an alarmingly high prevalence of STH among Orang Asli children and clearly brings out an urgent need to implement school-based de-worming programmes and other control measures like providing a proper sanitation, as well as a treated drinking water supply and proper health education regarding good personal hygiene practices. Such an integrated control program will help significantly in reducing the prevalence and intensity of STH in Orang Asli communities.

Keywords: Soil-transmitted helminths, Ascaris, Trichuris, Hookworm, Orang Asli, Malaysia

\footnotetext{
* Correspondence: halmekhlafi@yahoo.com

'Department of Parasitology, Faculty of Medicine, University of Malaya,

50603, Kuala Lumpur, Malaysia

${ }^{4}$ Department of Parasitology, Faculty of Medicine and Health Sciences, Sana'a

University, Sana'a, Yemen

Full list of author information is available at the end of the article
} 


\section{Background}

Soil-transmitted helminth (STH) infections are still considered to be the most prevalent infections of humankind. Ascaris lumbricoides, hookworm (Ancylostoma duodenale and Necator americanus) and Trichuris trichiura are the most common STH species with global prevalence of about 1000, 900 and 500 million cases, respectively [1,2]. Nowadays, STH has been classified among the most prevalent neglected tropical diseases (NTDs) as they persist exclusively in the poorest populations often living in remote, rural areas, urban slums or in conflict zones, and have been largely eliminated elsewhere and thus are often forgotten [3].

It is estimated that STH together with schistosomiasis represent about $40 \%$ of the disease burden caused by all tropical diseases, excluding malaria [4]. However, the morbidity caused by STH is most commonly associated with infections of moderate-to-heavy intensities [5,6]. Several studies have revealed the impact of STH infections as significant predictors of protein-energy malnutrition, iron deficiency anaemia (IDA), vitamin A deficiency (VAD) and poor academic performance among schoolchildren in different countries [7-10]. Moreover, these consequences may continue into adulthood with effects on the economic productivity which trap the communities at risk of infections in a cycle of poverty, underdevelopment and disease [11]. Hence, benefits of successful STH control programmes extend well beyond eliminating STH as they improve the nutritional and health status of the children as well as contribute to higher educational attainment, labour force participation, productivity, and income among the most vulnerable populations [12-14].

Despite the efforts and interventions to control STH infections, about $70 \%$ of school-aged children at risk of STH infections are still not covered by de-worming treatment [2]. Therefore, the global efforts towards controlling STH by targeting the de-worming of $75 \%$ of school-aged children living in endemic areas by the year 2010 was not reached and therefore, STH infections remain prevalent especially in rural areas of developing countries [2].

Malaysia has witnessed great socioeconomic and infrastructural development. However, the country is still plagued with many parasitic infections especially among impoverished rural dwellers. Although there is a significant reduction in the prevalence of STH infections in the urban areas [15], the trend in the rural areas, especially among Orang Asli populations remains largely unchanged since the 1920 s, with alarming high prevalence rates and prominent morbidity [5,16-20]. Thus, STH infections continue to have negative impacts on the public health particularly among Orang Asli children, and this may indicate the need for immediate and sustained action to save the lives and future of vulnerable children.
Within this context, we conducted this communitybased study to determine the current prevalence and the associated key factors of STH among Orang Asli children in rural Malaysia. It is hoped that findings of this study will assist public health officials to identify effective and integrated control measures to reduce the prevalence and intensity of STH in the rural communities.

\section{Methods}

\section{Study design}

A cross-sectional study was conducted among Orang Asli (Aborigines) population in Lipis district, Pahang. Data collection was carried out over a period of six months, from April to September 2011. The study has two parts; determining the prevalence, distribution and associated key factors of STH infections among Orang Asli children in randomly selected households, and evaluating the knowledge, attitude and practices (KAP) toward intestinal helminth infections among the heads of these households [21].

\section{Study area}

This study was carried out in the Lipis district of Pahang state, located at the center of Peninsular Malaysia, about $200 \mathrm{~km}$ northeast of Kuala Lumpur with a total area of $5,198 \mathrm{~km}^{2}$ and a total population of 87,200 people (2010 census). The climate is equatorial with hot-humid conditions and rainfall throughout the year. The vegetation is the thick rain forest type and there are few water streams in the area. This study was conducted in 13 Orang Asli villages namely Kuala Koyan, Sentoi, Kuala Kennip, Sarang, Samut, Kuala Milut, Tual Baru, Sat Baru, Chekai (Jerankuk), Ulu Milot, Tanjung Gahai, Sungai Padi and Semoi (Figure 1). The villages were selected from the available official village list in collaboration with the Department of Orang Asli Development (JAKOA) with consideration of the following criteria: located in rural area, accessible from the main roads and each village has more than 20 houses or $\geq 100$ residents.

\section{Study population}

This study was conducted among Orang Asli people resident in the selected villages. Orang Asli are the indigenous minority peoples of Peninsular Malaysia and the name, Orang Asli, is a Malay term translated as 'original or first people'. The total number of Orang Asli represents $0.7 \%$ of the country's total population, and mostly they are concentrated in the different states of Malaysia, mainly Pahang, Kelantan, Perak, Selangor and Negeri Sembilan. They are generally classified under three main groups distributed all over the country; Negrito, Senoi and Proto-Malay. Each group has its own culture and language; however, most of the Orang Asli can speak Malay language which is the official national language of 


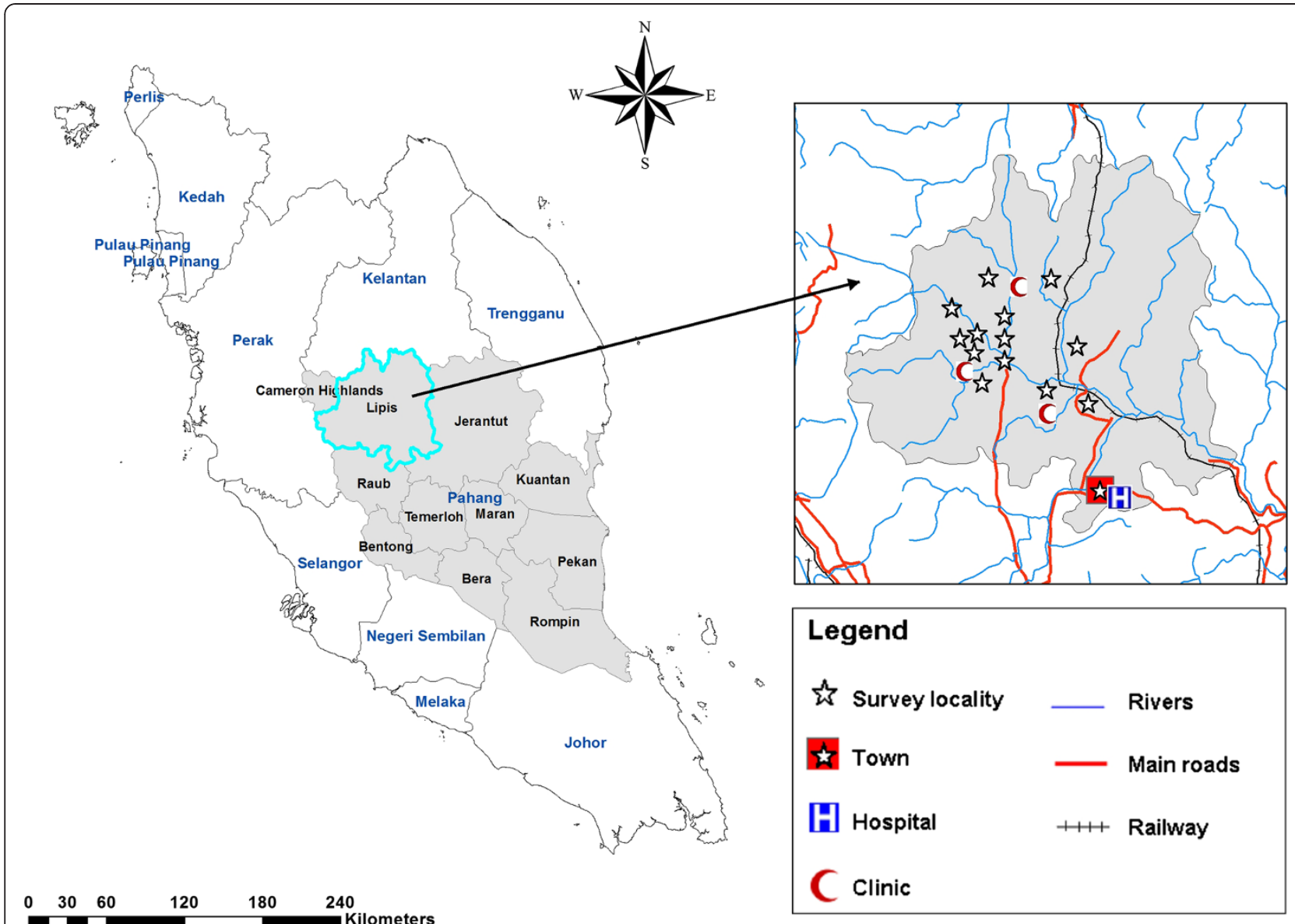

Figure 1 A geographic map showing Pahang state and location of the selected villages in Lipis, district.

Malaysia. The main sub-ethnic group residing in this area is the Semai and they belong to the Senoi ethnic group.

Out of 710 households, 215 households were selected randomly from the villages for this study. During the visits, there were 658 children in the target age range of $\leq 15$ years and all of them were invited to participate in this study. Of these children, 89 had refused to participate while 85 had not delivered stool samples in the next 2 days. Hence, 484 children had agreed voluntarily to participate in this study and delivered stool samples for examination (Figure 2).

\section{Questionnaire survey}

A validated structured questionnaire has been designed and developed to collect information on the demographic, socioeconomic and environmental background, personal hygiene and practices, health status and the KAP of the participants towards intestinal helminth infections. Attempting to cover all possible factors associated with intestinal helminths, the questionnaire was designed in English language (original version) by the principal researchers and then translated to Malay (forward translation) by a professor of parasitology who was bilingual (English and Malay). The Malay version of the questionnaire was then back-translated to English by another bilingual professor who was also blinded to the original questionnaire. Then, the principal researchers assessed semantic equivalence between the 2 English versions (Original and the back-translated versions) for each item and made the appropriate changes of the item descriptions in the Malay version. The final Malay version was reviewed by two different experts from different institutions to check for face validity. Before starting the survey, the questionnaire was pilot tested among 28 Orang Asli people in Ulu Batu village, Selangor, Malaysia. The consistency and reliability of the questionnaire was assessed and the results showed good consistency and high test-retest reliability.

The heads of households were interviewed (face-toface interviews) by two health assistants from JAKOA and from the Department of Parasitology, University of Malaya. Both assistants were trained on the purpose of the study and on how to administer the questionnaire. During the interviews, observation was made by another researcher on the personal hygiene of the children and 


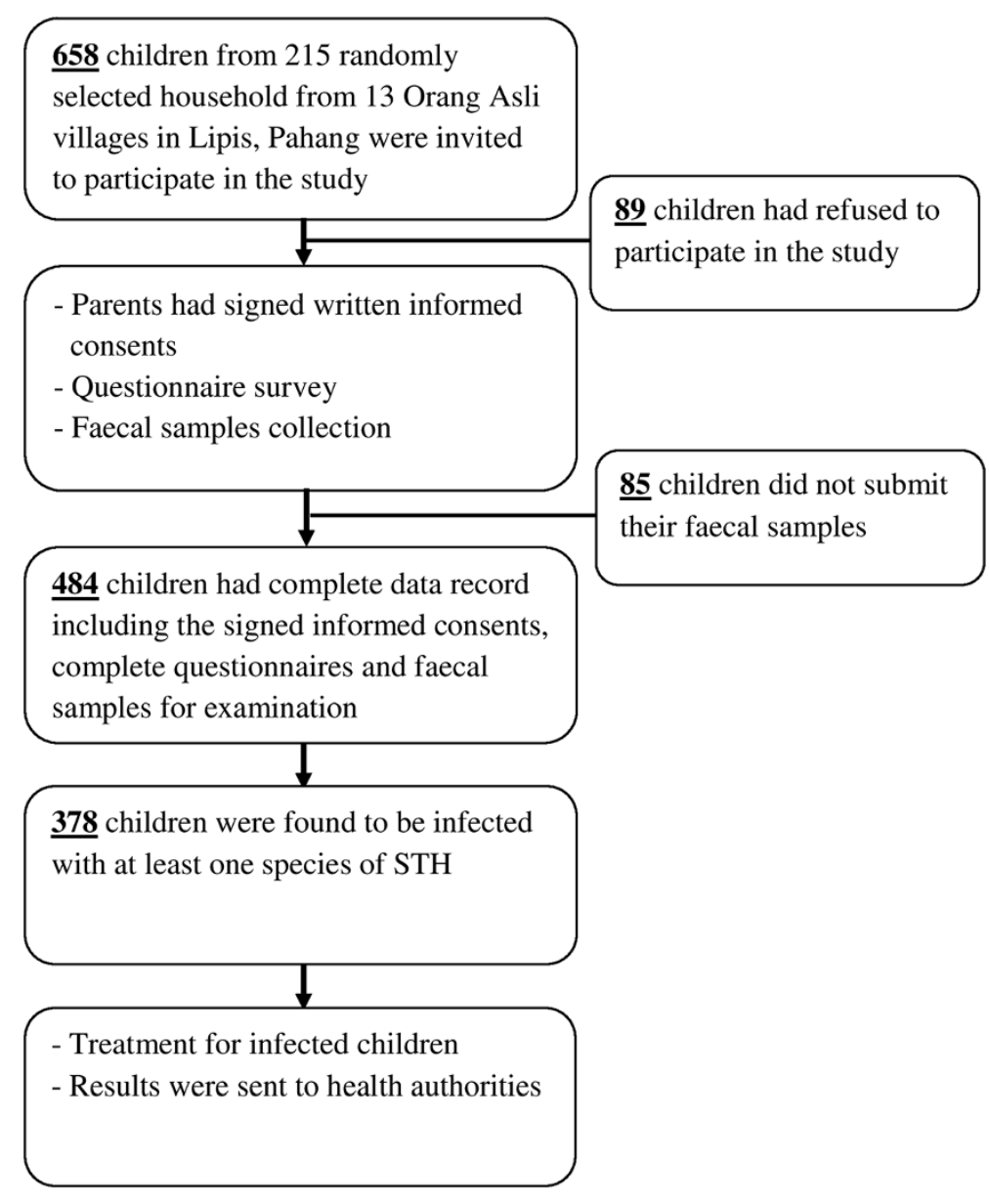

Figure 2 Flow chart of the participation and compliance in the present study.

household cleanliness including the availability and usage of toilets, piped water, cutting nails, wearing shoes when outside the house, washing hands and clothes.

\section{Parasitology}

Fresh faecal samples were collected in clearly labeled containers with wide mouth and screw-caps. The children were instructed to bring their early morning stool samples the next day. The collected samples were transported for examination at the stool processing laboratory in the Department of Parasitology, University of Malaya. The examination was carried out by using three different techniques; formalin-ether sedimentation technique in order to increase the detection rates especially when the parasites are found in few numbers [22], Kato Katz technique for egg count to estimate the intensity of infections [23], and Harada Mori culture techniques to detect hookworm larvae in light infections [24]. Sample was reported as positive if eggs and/or larvae were detected by any of the three techniques. However, when the samples were negative by Kato Katz and found to be positive either by formalin-ether sedimentation technique or
Harada Mori culture, the calculation of egg counts was based on the number of eggs/larvae detected by these 2 methods. To reduce human error, duplicate slides were prepared from each sample for each diagnostic technique and the slides were read by two different microscopists. The average of the readings was used in this report. The intensity of infection was recorded as eggs per gram (epg) of faeces and it was graded according to the criteria proposed by the WHO [23].

\section{Data analysis}

Data was double-entered by two different researchers into Microsoft Office Excel 2007 spreadsheets. Then, a third researcher cross-checked the two data sets for accuracy and created a single data set. Data analysis was performed by using Statistical Package for Social Sciences for Windows (SPSS) version 13. Demographic, socioeconomic, environmental and behavioural characteristics were treated as categorical variables and presented as frequencies and percentages. Pearson's Chi Square test and Fisher's Exact test were used to test the associations of STH prevalence with demographic, 
socioeconomic, environmental and behavioural factors. Odd ratios (OR) and 95\% confidence intervals $(\mathrm{CI})$ were computed. In order to identify the risk factors significantly associated with each STH infection (Ascaris, Trichuris and hookworm), all variables that showed associations with $P \leq 0.25$ in the univariate analysis were used to develop a multivariate logistic regression model as suggested by Bendel and Afifi [25].

\section{Ethical consideration}

The protocol of this study was approved by the Medical Ethics Committee of the University of Malaya Medical Centre, Malaysia (Reference Number: 788.74). Before the commencement of the study, meetings were held with the head of each village to provide information about the objectives and protocol of the study and their consents were obtained. During fieldwork, the objectives and procedures of the study were explained to the heads of the sampled households. They were informed that their participation was totally voluntary and that they could decide to withdraw from the study at any time without giving any reason whatsoever. Thus, written and signed or thumb-printed informed consents were obtained from all adult participants before starting the survey. Similarly, written and signed or thumb-printed informed consents were taken from parents or guardians, on behalf of their children. All the infected children were treated with a single dose of $400 \mathrm{mg}$ albendazole (Zentel ${ }^{\circledR}$ ) tablets. Each child chewed the tablets before swallowing them with some water, while being observed by a researcher and medical officer (Direct Observed Therapy) [23].

\section{Results}

\section{General characteristics of the households}

Four hundred and eighty four children aged between 1 and 15 years, with a median age of 7 years (IQR 4-10), and living in 215 households from 13 villages in Lipis, Pahang had participated in this study. Of those, 51.4\% were males and $48.6 \%$ were females. The age-group distribution showed that $60.5 \%$ were aged $\geq 6$ years while $39.5 \%$ were $<6$ years of age. About two thirds of the fathers had at least primary education with $16.3 \%$ of them having secondary education. On the other hand, about half of the mothers had primary education while $17.7 \%$ had secondary education. Moreover, about one third of the households had low monthly income $(<$ RM500). Most of the houses were made of wood or bamboo and raised on stilts with palm thatched roof and bamboo planks for the wall and floor. About half of the houses had piped water supply (gravity-fed) while $89.8 \%$ had electricity. Other sources of water supply for drinking, cooking and washing included rivers, rain and deep wells. Moreover, about half of the houses had toilets; most of the toilets were pour flush toilets connected to a sewer or a septic tank, and $25 \%$ were pit latrines. The majority of Orang Asli people were engaged in agriculture, forestry, fishing and related occupations. A high proportion of them were employed as workers in rubber and oil palm plantations while about 5\% were farmers. The general characteristics of the children who participated in this study are shown in Table 1.

\section{Prevalence and distribution of STH infections}

Faecal samples were examined for the presence of intestinal helminths including STH eggs or larvae. Overall, 378 (78\%) children were found to be infected with at least one species of STH. The result as shown in Table 2, indicated that the predominant species was $T$. trichiura with a prevalence rate of $71.7 \%$, followed by $A$. lumbricoides (37.4\%) and then hookworms (17.6\%). The prevalence of these 3 species increased with age. On the other hand, the prevalence of STH infections among males and females was almost similar. Moreover, 39\% of STH infections were single infections with only 1 species, while the remaining $61 \%$ were mixed infections by a combination of 2 or 3 species. Ascariasis and trichuriasis were the most prevalent co-infection representing $22 \%$ of the overall prevalence followed by the combination of the triad of helminths (9.0\%).

Almost one third (32.3\%) and two-thirds (66.9\%) of the trichuriasis were of heavy and moderate intensity, respectively (Table 2). Similarly, $8.3 \%$ and $69.6 \%$ of the infections by $A$. lumbricoides were of heavy and moderate intensity, respectively. Moreover, the majority of hookworm cases

Table 1 General characteristics of Orang Asli children who participated in the study $(n=484)$

\begin{tabular}{ll}
\hline Characteristics & $\mathbf{n}(\%)$ \\
\hline Age groups & $191(39.5)$ \\
$<6$ years (pre-school) & $293(60.5)$ \\
$\geq 6$ years (school-age) & \\
Gender & $249(51.4)$ \\
Males & $235(48.6)$ \\
Females & \\
Socioeconomic status & $331(66.6)$ \\
Fathers' education level (at least primary) & $264(52.1)$ \\
Mothers' education level (at least primary) & $335(65.8)$ \\
Low household income (<RM500) & $120(24.1)$ \\
Working fathers & $23(4.5)$ \\
Working mothers & $308(60.5)$ \\
Large family size ( $\geq 7$ members) & $263(51.3)$ \\
Piped water supply & $473(92.7)$ \\
Electricity & $274(53.8)$ \\
Presence of toilet in house &
\end{tabular}

All values are number (\%). RM, Malaysian Ringgit; (US\$1 = RM3.15). 
Table 2 Prevalence and intensity of STH infections among Orang Asli children in Lipis, Pahang $(\mathbf{n}=484)$

\begin{tabular}{|c|c|c|c|c|c|c|c|c|c|}
\hline \multirow[t]{3}{*}{ Intensity of infection* } & \multicolumn{9}{|c|}{ Type of infection } \\
\hline & \multicolumn{3}{|c|}{ Trichuriasis } & \multicolumn{3}{|c|}{ Ascariasis } & \multicolumn{3}{|c|}{ Hookworm infection } \\
\hline & $\mathrm{N}$ & $\%$ & Mean (epg) & $n$ & $\%$ & Mean (epg) & $\mathrm{n}$ & $\%$ & Mean (epg) \\
\hline Light & 3 & 0.9 & 900 & 40 & 22.1 & 3,392 & 69 & 81.2 & 647 \\
\hline Moderate & 232 & 66.9 & 4,849 & 126 & 69.6 & 18,429 & 8 & 9.4 & 2,704 \\
\hline Heavy & 112 & 32.3 & 17,441 & 15 & 8.3 & 60,528 & 8 & 9.4 & 6,405 \\
\hline Overall & 347 & 71.1 & 8,868 & 181 & 37.4 & 18,594 & 85 & 17.6 & 1,339 \\
\hline
\end{tabular}

* Classified according to the criteria proposed by WHO [21]. epg, Eggs per gram.

were of light intensity (81.2\%). Moreover, Giardia intestinalis and Entamoeba histolytica/dispar were detected in $17.6 \%$ and $15 \%$ of the samples, respectively.

\section{Factors associated with STH infections}

Results of univariate and multivariate analyses for the association of STH infections (trichuriasis, ascariasis and hookworm infection) with demographic, socioeconomic, environmental and behavioural factors are shown in Tables 3, 4, 5 and 6 .

Table 3 shows that the prevalence of trichuriasis was significantly higher among school-age children (80.5\%; 95\% $\mathrm{CI}=75.6,84.7)$ when compared with pre-school children (58.1\%; 95\% CI = 51.0, 64.9). Similarly, children who use unsafe sources for drinking water had higher prevalence (80.5\%; 95\% CI $=75.0,85.1$ ) when compared to those who use piped water $(63.3 \%$; $95 \% \mathrm{CI}=57.2,69.1)$. Moreover, the prevalence of infection was significantly higher among children who do not wash their hands after defecation (77.0\%; 95\% CI $=73.3,82.4$ ) and those who walk barefooted $(78.0 \%$; $95 \% \mathrm{CI}=72.7,83.3)$ when compared to those who practise hand washing after defecation (68.3\%; $95 \% \mathrm{CI}=62.7,72.6)$ and those always wear shoes when outside the house $(67.6 \%$; $95 \% \mathrm{CI}=62.0,71.6)$. The results of multiple logistic regression for the significant factors (Table 6) confirmed that school-age children were at higher odds for Trichuris infection when compared with pre-school children by 3.6 times $(\mathrm{OR}=3.6 ; 95 \% \mathrm{CI}=2.3$, 5.5). Moreover, children who used unsafe sources for drinking water had significantly higher odds of having trichuriasis when compared to those living in houses supplied with piped water $(\mathrm{OR}=2.9 ; 95 \% \mathrm{CI}=1.9,4.5)$.

Table 4 shows that the prevalence of ascariasis among school-age children $(43.0 \%$; $95 \% \mathrm{CI}=37.5$, 48.7) was significantly higher than the prevalence among pre-school children (28.8\%; 95\% CI $=22.9,35.6)$. Similarly, the prevalence of ascariasis among children who live in families with $\geq 7$ members (40.9\%; 95\% CI $=37.7$, 46.6) was significantly higher than the prevalence among those living in smaller families with $<7$ members (31.7\%; 95\% $\mathrm{CI}=25.5$, 36.2). Moreover, the prevalence of ascariasis was significantly higher among children who live in houses without toilets $(44.5 \%$; $95 \% \mathrm{CI}=38.1,51.1)$ and those using unsafe sources of drinking water (43.6\%; $95 \% \mathrm{CI}=38.1,50.0)$ when compared to those living in houses with toilets $(31.6 \%$; $95 \% \mathrm{CI}=26.3,37.4)$ and piped water supply $(31.5 \%$; $95 \% \mathrm{CI}=26.0,37.2)$. A significant association between ascariasis and personal hygiene practices was also reported as the prevalence was found to be higher among children who do not wash their hands before eating (44.4\%; 95\% CI $=38.7,50.3$ ) when compared to those who practise hand washing before eating $(27.8 \% ; 95 \% \mathrm{CI}=22.1,34.3)$. Similarly, children who do not wash their hands after defecation (50.8\%; 95\% CI $=43.8$, 57.8) had significantly higher prevalence of ascariasis when compared with those who wash their hands $(28.7 \%$; 95\% CI $=23.8,34.1)$.

Five factors associated significantly with ascariasis were retained by multiple logistic regression model analysis (Table 6). School-age children were at twice the odds of Ascaris infection when compared with preschool children $(95 \% \mathrm{CI}=1.3,2.9)$. Similarly, not washing hands after defecation increased children's odds for ascariasis when compared with always washing hands after defecation by 2.6 times $(95 \% \mathrm{CI}=1.8,3.9)$. Children who did not have piped water facility in their houses had $2.2(95 \% \mathrm{CI}=1.4,3.2)$ times the odds of having Ascaris infection. Likewise, children who lived in houses without functioning toilets were found to have higher odds of having Ascaris infection as compared with their counterparts $(\mathrm{OR}=1.7 ; 95 \% \mathrm{CI}=1.2,2.6)$. Moreover, children of families with $\geq 7$ members had significantly higher odds $(\mathrm{OR}=1.7 ; 95 \% \mathrm{CI}=1.1,2.5)$ of having Ascaris infection as compared to those who live in families with $<7$ members.

Table 5 shows that school-age children had significantly higher prevalence of hookworm infection (23.5\%; $95 \% \mathrm{CI}=19.1,28.7)$ when compared to pre-school children $(8.4 \%$; $95 \% \mathrm{CI}=5.2,13.2)$. Similarly, the prevalence of hookworm among children who lived in houses without toilets $(23.4 \% ; 95 \% \mathrm{CI}=18.3,29.4)$ and those who did not practise hand washing before eating (21.9\%; 95\% $\mathrm{CI}=17.4,27.1)$ was almost twice as much as those having toilets in their houses $(12.8 \% ; 95 \% \mathrm{CI}=9.3,17.3)$ and those that wash their hands before eating (11.7\%; 95\% $\mathrm{CI}=8.0,16.8)$. Moreover, the results showed that the prevalence of infection was significantly associated with 
Table 3 Univariate analysis of factors associated with trichuriasis among Orang Asli children in Lipis, Pahang ( $n=484$ )

\begin{tabular}{|c|c|c|c|c|}
\hline \multirow[t]{3}{*}{ Variables } & \multicolumn{2}{|c|}{ Trichuriasis } & \multirow[t]{3}{*}{ OR(95\% Cl) } & \multirow[t]{2}{*}{$P$ value } \\
\hline & No. & Infected & & \\
\hline & ex & n (\%) & & \\
\hline
\end{tabular}

\section{Age}

\section{School-age}

Pre-school-age

Gender

Male

Female

235

Father's educational levels

Non educated $\quad 159$

( $<6$ years)

Educated ( $\geq 6$ years) $\quad 314$

Mother's educational levels

Non educated 233

( $<6$ years)

Educated ( $\geq 6$ years) $\quad 249$

Father's employment status

Not working 360

Working 113

Mother's employment status

Not working 463

Working

Household monthly income

$<$ RM500

322

$\geq$ RM500

162

Family size

$\geq 7$ members (large) 298

$<7$ members

Presence of toilet in house

No 218

Yes

266

Presence of domestic animals

Yes 363

No

Source of drinking water

Unsafe source (river, rain) 236

Safe source (pipe) 248

Washing hands before eating

No 279

Yes

205

Washing hands after defecation

$\begin{array}{lllll}\text { No } & 191 & 147(77.0) & 1.6(1.0,2.4) & 0.038^{*} \\ \text { Yes } & 293 & 200(68.3) & 1\end{array}$

Table 3 Univariate analysis of factors associated with trichuriasis among Orang Asli children in Lipis, Pahang ( $n=484)$ (Continued)

Indiscriminate defecation

$\begin{array}{llllll}\text { Yes } & 323 & 225(69.7) & 0.7(0.5,1.1) & 0.159 \\ \text { No } & 161 & 122(75.8) & 1\end{array}$

Eating soil habit (Geophagy)

$\begin{array}{lllll}\text { Yes } & 120 & 93(77.5) & 1.5(0.9,0.2) & 0.104 \\ \text { No } & 364 & 254(69.8) & 1\end{array}$

Cutting nails periodically

$\begin{array}{lrrrrr}\text { No } & 235 & 166(70.6) & 0.9(0.6,1.3) & 0.616 \\ \text { Yes } & 249 & 181(72.7) & 1 & \\ \text { Wearing shoes when outside } & & & \\ \text { No } & 191 & 149(78.0) & 1.7(1.1,2.6) & 0.013^{*} \\ \text { Yes } & 293 & 198(67.6) & 1\end{array}$

Washing fruits before eating

$\begin{array}{llllll}\text { No } & 268 & 191(71.3) & 1.0(0.6,1.4) & 0.817 \\ \text { Yes } & 216 & 156(72.2) & 1\end{array}$

Washing vegetables before eating

$\begin{array}{lllll}\text { No } & 156 & 113(72.4) & 1.1(0.7,1.6) & 0.803 \\ \text { Yes } & 328 & 234(71.3) & 1\end{array}$

Boiling water before drinking

\begin{tabular}{lcccc} 
No & 151 & $110(72.8)$ & $1.1(0.7,1.7)$ & 0.704 \\
Yes & 160 & $120(75.0)$ & 1 \\
\hline RM, Malaysian Ringgit; (US\$1 = RM3.15). OR, Odds ratio. Cl, Confidence interval. \\
* Significant association $(P<0.05)$.
\end{tabular}

indiscriminate defecation, the prevalence of hookworm infection was significantly higher among children who used nearby rivers or bushes for defecation (20.7\%; 95\% $\mathrm{CI}=17.2,25.7)$ when compared to those who use the toilets $(11.2 ; 95 \% \mathrm{CI}=7.0,16.4)$. Although the prevalence of hookworm was higher among those who do not boiling drinking water ( $22.5 \%)$ compared to those who practise boiling it (15.3\%) and among children living in houses without safe sources for drinking water (20.8\%) when compared to those who live in houses with piped water supply $(11.7 \%)$, these differences were not statistically significant $(P>0.05)$.

Multiple logistic regression model retained 4 factors associated significantly with hookworm infection (Table 6). Those of school-age were at greater odds for hookworm infection by 3.6 times as compared to pre-school children $(95 \% \mathrm{CI}=1.9,6.5)$. Similarly, the results showed that children who live in houses without functioning toilets had 2.1 times the odds $(\mathrm{OR}=2.1 ; 95 \% \mathrm{CI}=1.3,3.5)$, using unsafe sources for drinking water had 1.7 times odds $(\mathrm{OR}=1.7 ; 95 \% \mathrm{CI}=1.1,2.9)$, and not washing hands before eating had 2.2 times odds $(\mathrm{OR}=2.2 ; 95 \% \mathrm{CI}=1.3,3.8)$ of having hookworm infection when compared with their counterparts. 
Table 4 Univariate analysis of factors associated with ascariasis among Orang Asli children in Lipis, Pahang ( $n=484)$

\begin{tabular}{ll}
\hline Variables & Ascariasis \\
$\begin{array}{l}\text { No. } \\
\text { examined } \frac{\text { Infected }}{\mathrm{n}(\%)}\end{array}$
\end{tabular}

\section{Age}

$\begin{array}{lllll}\text { School-age } & 293 & 126(43.0) & 1.9(1.3,2.8) & 0.002^{*} \\ \text { Pre-school-age } & 191 & 55(28.8) & 1 & \\ \text { Gender } & & & & \\ \text { Male } & 249 & 92(36.9) & 1.0(0.7,1.4) & 0.834 \\ \text { Female } & 235 & 89(37.9) & 1 & \end{array}$

Father's educational levels

\begin{tabular}{|c|c|c|c|c|}
\hline $\begin{array}{l}\text { Non educated }(< \\
6 \text { years) }\end{array}$ & 159 & $60(37.7)$ & $1.0(0.7,1.5)$ & 0.973 \\
\hline Educated ( $\geq 6$ years) & 314 & 119 (37.9) & 1 & \\
\hline \multicolumn{5}{|c|}{ Mother's educational levels } \\
\hline $\begin{array}{l}\text { Non educated }(< \\
6 \text { years) }\end{array}$ & 233 & $88(37.8)$ & $1.0(0.7,1.5)$ & 0.924 \\
\hline Educated ( $\geq 6$ years) & 249 & $93(37.3)$ & 1 & \\
\hline \multicolumn{5}{|c|}{ Father's employment status } \\
\hline Not working & 360 & $133(36.9)$ & $1.2(0.8,1.8)$ & 0.472 \\
\hline Working & 113 & $46(40.7)$ & 1 & \\
\hline \multicolumn{5}{|c|}{ Mother's employment status } \\
\hline Not working & 463 & $175(37.8)$ & $0.8(0.3,2.1)$ & 0.583 \\
\hline Working & 19 & $6(31.6)$ & 1 & \\
\hline \multicolumn{5}{|c|}{ Household monthly income } \\
\hline RM500 & 322 & $121(37.6)$ & $1.0(0.7,1.5)$ & 0.908 \\
\hline RM500 & 162 & $60(37.0)$ & 1 & \\
\hline
\end{tabular}

Family size

$\geq 7$ members (large) $\quad 298$

$<7$ members

Presence of toilet in house

$\begin{array}{lllll}\text { No } & 218 & 97(44.5) & 1.7(1.2,2.5) & 0.003^{*} \\ \text { Yes } & 266 & 84(31.6) & 1\end{array}$

Presence of domestic animals

$\begin{array}{lllll}\text { Yes } & 363 & 138(38.0) & 1.1(0.7,1.7) & 0.625 \\ \text { No } & 121 & 43(35.5) & 1\end{array}$

Source of drinking water

Unsafe source 236

(river, rain)

$103(43.6) \quad 1.7(1.2,2.5) \quad 0.006^{*}$

$\begin{array}{llll}\text { Safe source (pipe) } \quad 248 & 78(31.5) & 1\end{array}$

Washing hands before eating

$\begin{array}{lllll}\text { No } & 279 & 124(44.4) & 2.1(1.4,3.1) & <0.001 * \\ \text { Yes } & 205 & 57(27.8) & 1\end{array}$

Washing hands after defecation

$\begin{array}{llllll}\text { No } & 191 & 97(50.8) & 2.6(1.8,3.8) & <0.001^{*} \\ \text { Yes } & 293 & 84(28.7) & 1\end{array}$

Table 4 Univariate analysis of factors associated with ascariasis among Orang Asli children in Lipis, Pahang ( $\mathrm{n}=\mathbf{4 8 4}$ ) (Continued)

Indiscriminate defecation

$\begin{array}{lllll}\text { Yes } & 323 & 127(39.3) & 1.3(0.9,1.9) & 0.216 \\ \text { No } & 161 & 54(33.5) & 1\end{array}$

Eating soil habit (Geophagy)

$\begin{array}{lllll}\text { Yes } & 120 & 47(39.2) & 1.1(0.7,1.7) & 0.644 \\ \text { No } & 364 & 134(36.8) & 1\end{array}$

Cutting nails periodically

$\begin{array}{lllll}\text { No } & 235 & 90(38.3) & 1.1(0.8,1.6) & 0.691 \\ \text { Yes } & 249 & 91(36.5) & 1\end{array}$

Wearing shoes when outside

$\begin{array}{lllll}\text { No } & 191 & 79(41.4) & 1.3(0.9,1.9) & 0.146 \\ \text { Yes } & 293 & 102(34.8) & 1\end{array}$

Washing fruits before eating

$\begin{array}{lllll}\text { No } & 268 & 102(38.1) & 1.1(0.7,1.5) & 0.737 \\ \text { Yes } & 216 & 79(36.6) & 1\end{array}$

Washing vegetables before eating

$\begin{array}{lllll}\text { No } & 156 & 67(42.9) & 1.4(0.9,2.1) & 0.082 \\ \text { Yes } & 328 & 114(34.8) & 1\end{array}$

Boiling water before drinking

\begin{tabular}{lllll} 
No & 151 & $60(39.7)$ & $1.2(0.8,1.7)$ & 0.474 \\
Yes & 333 & $121(36.3)$ & 1 & \\
\hline
\end{tabular}

RM, Malaysian Ringgit; (US\$1 = RM3.15). OR, Odds ratio. Cl, Confidence interval. * Significant association $(P<0.05)$.

\section{Discussion}

Soil-transmitted helminth (STH) infection remains a major public health problem among the Malaysian Orang Asli population, thereby possibly contributing to their overall backwardness and low productivity. The adherence of these people to be confined within the rainforest away from other people possibly contributes to their limited integration into Malay society, poor public enlightenment and low level of education. The findings of the present study showed high prevalence of STH infections with $78 \%$ of the children was infected with at least one STH species. The predominant parasite was T. trichiura, followed by A. lumbricoides, while hookworm was the least prevalent. Although, Strongyloides stercoralis larvae were detected in $7.1 \%$ of soil samples in the study area (Lipis district), S. stercoralis infection is not endemic in Malaysia and it usually occurs as sporadic cases $[26,27]$. These findings are consistent with the reports from previous studies among Orang Asli people in Malaysia $[5,16,17,28]$. However, our findings were contrary to some recent reports from neighbouring countries such as Thailand (mainly southern region) where hookworms were reported as the most prevalent species $[29,30]$ and China where ascariasis was most prevalent [31]. 
Table 5 Univariate analysis of factors associated with hookworm infection among Orang Asli children in Lipis, Pahang $(n=484)$

\begin{tabular}{llll}
\hline Variables & $\begin{array}{l}\text { Hookworm } \\
\text { infection }\end{array}$ & OR(95\% Cl) & $\begin{array}{l}\mathrm{P} \\
\text { value }\end{array}$ \\
\cline { 2 - 3 } & $\begin{array}{l}\text { No. } \\
\text { examined } \frac{\text { Infected }}{\mathrm{n}(\%)}\end{array}$ & \\
\hline
\end{tabular}

Age

School-age

Pre-school-age

293

Gender

Male

Female

Father's educational levels

Non educated $(<6$ years) 159

Educated ( $\geq 6$ years) $\quad 314$

Mother's educational levels

Non educated $(<6$ years) 233

Educated ( $\geq 6$ years) $\quad 249$

Father's employment status

Not working $\quad 360$

Working

113

Mother's employment status

Not working 463

Working

19

Household monthly income

$<$ RM500

322

$\geq$ RM500

162

Family size

$\geq 7$ members (large) 298

$<7$ members

Presence of toilet in house

No 218

Yes 266

Presence of domestic animals

Yes 363

No

121

Source of drinking water

Unsafe source (river, rain) 236

Safe source (pipe)

248

Washing hands before eating

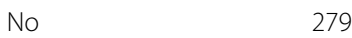

Yes

Washing hands after defecation

$\begin{array}{lllll}\text { No } & 191 & 32(16.8) & 0.9(0.6,1.5) & 0.706 \\ \text { Yes } & 293 & 53(18.1) & 1\end{array}$

$16(8.4)$

$49(19.7) \quad 1.4(0.8,2.2) \quad 0.208$

$36(15.3) \quad 1$

$54(16.8) \quad 0.9(0.5,1.4) \quad 0.519$

$31(19.1) \quad 1$

$53(17.8) \quad 1.0(0.6,1.7) \quad 0.870$

$32(17.2) \quad 1$
Table 5 Univariate analysis of factors associated with hookworm infection among Orang Asli children in Lipis, Pahang ( $\mathbf{n}=\mathbf{4 8 4})$ (Continued)

Indiscriminate defecation

$\begin{array}{lllll}\text { Yes } & 323 & 67(20.7) & 2.1(1.2,3.6) & 0.009^{*} \\ \text { No } & 161 & 18(11.2) & 1\end{array}$

Eating soil habit (Geophagy)

Yes 120

No 364

$25(20.8) \quad 1.3(0.8,2.2) \quad 0.277$

Cutting nails periodically

$\begin{array}{lllll}\text { No } & 235 & 37(15.7) & 0.8(0.5,1.3) & 0.307 \\ \text { Yes } & 249 & 48(19.3) & 1\end{array}$

Wearing shoes when outside

$\begin{array}{lllll}\text { No } & 191 & 38(19.9) & 1.3(0.8,2.1) & 0.276 \\ \text { Yes } & 293 & 47(16.0) & 1\end{array}$

Washing fruits before eating

$\begin{array}{lllll}\text { No } & 268 & 46(17.2) & 0.9(0.6,1.5) & 0.798\end{array}$

Yes $\quad 216 \quad 39(18.1) \quad 1$

Washing vegetables before eating

$\begin{array}{lllll}\text { No } & 156 & 21(13.5) & 0.6(0.4,1.1) & 0.102 \\ \text { Yes } & 328 & 64(19.5) & 1\end{array}$

Boiling water before drinking

\begin{tabular}{lcccc} 
No & 151 & $34(22.5)$ & $1.6(0.99,2.6)$ & 0.054 \\
Yes & 333 & $51(15.3)$ & 1 \\
\hline RM, Malaysian Ringgit; (US\$1 = RM3.15). OR, Odds ratio. Cl, Confidence interval. \\
* Significant association $(P<0.05)$.
\end{tabular}

The high prevalence rates of $T$. trichiura infection reported in this study could be attributed to the low efficacy of the benzimidazole anthelminthics drugs against this worm as reported previously [32,33]. The adult worm usually live embedded in the walls of the lumen of their host, hence it is difficult to be killed and expelled by a single dose of anthelminthics. Researchers therefore fear that anthelminthics resistance might be emerging in $T$. trichiura $[34,35]$. On the other hand, the low prevalence rate of hookworm reported in our study might be connected to the nature of the soil in several parts of Malaysia which is the heavy clayey-loam type. This type of soil was found to be unsuitable for hookworm larval development [36,37].

The findings of the current study also revealed that almost all, three quarters and one fifth of the total infections by $T$. trichiura, A. lumbricoides and hookworm, respectively, were of moderate-to-heavy intensities. This is higher than the prevalence reported by previous studies conducted among the Orang Asli [5,16,17]. This prevalence is alarming especially considering the fact that clinical manifestations and other consequences of these infections tend to be positively correlated with the 
Table 6 Multivariate analysis of factors associated with STH infections among Orang Asli children in Lipis, Pahang ( $n=484)$

\begin{tabular}{|c|c|c|c|c|c|c|c|c|c|}
\hline \multirow[t]{2}{*}{ Variables } & \multicolumn{3}{|l|}{ Trichuriasis } & \multicolumn{3}{|l|}{ Ascariasis } & \multicolumn{3}{|c|}{ Hookworm infections } \\
\hline & Adjusted OR & $95 \% \mathrm{Cl}$ & $P$ & Adjusted OR & $95 \% \mathrm{Cl}$ & $P$ & Adjusted OR & $95 \% \mathrm{Cl}$ & $P$ \\
\hline School-age & 3.6 & $2.3,5.5$ & $<0.001$ & 1.9 & $1.3,2.9$ & 0.003 & 3.6 & $1.9,6.5$ & $<0.001$ \\
\hline Absence of toilet in house & - & - & - & 1.8 & $1.2,2.6$ & 0.005 & 2.1 & $1.3,3.5$ & 0.003 \\
\hline Source of drinking water (unsafe water) & 2.9 & $1.9,4.5$ & $<0.001$ & 2.2 & $1.4,3.2$ & $<0.000$ & 1.7 & $1.1,2.9$ & 0.032 \\
\hline Not washing hands before eating & - & - & - & - & - & - & 2.2 & $1.3,3.8$ & 0.004 \\
\hline Not washing hands after defecation & - & - & - & 2.6 & $1.8,3.9$ & $<0.001$ & - & - & - \\
\hline Large family size ( $\geq 7$ members) & - & - & - & 1.7 & $1.1,2.5$ & 0.016 & - & - & - \\
\hline
\end{tabular}

OR, Odds ratio. $\mathrm{Cl}$, Confidence interval.

burden of infection [5,6,31]. Besides the continuous exposure to the infections in these communities, the majority of the children did not receive any anthelmintic drugs in the last 12 months. In the absence of effective control and preventive measures, it is more likely that STH infections will continue to have devastating consequences and public health implications in these communities.

The World Health Organization is aware that the elimination of STH infections in endemic communities around the world may not be a feasible proposition; hence effort is geared towards the reduction of prevalence and intensity of infection to a low level. Endemic communities for STH are classified into 3 transmission categories for the adoption of treatment strategy in preventive chemotherapy; category I (high), category II (medium), and category III (low) [2]. Based on this classification, our study area and most probably all Orang Asli areas in Peninsular Malaysia fall within the first category (high risk communities), with STH prevalence of more than $50 \%$ and more than $10 \%$ of the infections being of heavy intensity. Hence, this high prevalence calls for urgent interventions particularly considering the fact that these infections lead to malnutrition and growth retardation [7,31], poor school performance [38], high school absenteeism rate [39], IDA and VAD [40,41], and overall poor productivity [42].

The present study investigated the possible factors associated with STH infections (trichuriasis, ascariasis and hookworm infection) among the studied children and revealed that age (school-age), absence of toilet and piped water supply in the household, large family size ( $\geq 7$ members), and not washing hands before eating and after defecation are the key factors that found to be associated with the three STH species. Many previous studies, including our previous published reports, have investigated and presented the risk factors of STH in different ways; either for overall intestinal parasitic infections (protozoa \& helminth) or for only one species of STH or for the heavy burden of overall STH infections. In order to develop an integrated control programme, the current study attempted to provide a complete picture and identified the significant associated key factors of the three STH species within the same community. However, our findings are in agreement with previous studies conducted in Malaysia [5,16,28] and abroad [30,43-46]. School-age children may have more exposure to the sources of infections due to their excessive mobility as compared to the pre-school children who usually receive more parental care. Moreover, if school environment is unhygienic this may also contribute to the transmission of these parasites.

In addition, poor personal hygiene including not washing hands before eating and after defecation is well documented as a significant risk factor of intestinal parasitic/ bacterial/viral infections $[45,47]$. Given the fact that the infective stages of these helminths are found in soil, washing hands before eating will help significantly in preventing these infections especially among children who love to play with soil.

In Malaysia, all Orang Asli communities are located close to rivers which are considered essential for Orang Asli life as they use water from streams for most of their daily activities (swimming, cooking, drinking, bathing and washing). However, rivers are also their preferred site for defecation and the practice of defecating near the streams by the residents (especially children) in these communities has been noted by other workers $[5,28]$. Thus, the untreated water is always likely to be contaminated with parasites eggs and/or cysts and its usage for household activities enhances the likelihood of infections. Moreover, the lack of functioning toilet facilities in the house contributes to the spread of intestinal parasitic infections. Overall, our findings showed that school-age, using unsafe sources for drinking water and lack of toilets in the house increases the odds of Trichuris, Ascaris and hookworm infections by about 2 to 3 times among these children.

Our findings also showed that children who belong to large families ( $\geq 7$ members) were at higher odds of $A s$ caris infection compared to children from smaller families. This finding is consistent with previous studies [16,48]. The horizontal spread or the focal transmission of 
infection among family members in the vicinity of the home may explain this finding. Moreover, a significant association between intestinal parasitic infections and the presence of other infected family members was reported [49].

The associated key factors identified by the present study are the main focus of effective STH control programmes [4]. In Malaysia, the national mass de-worming programme using a single dose of pyrantel pamoate once or twice a year was discontinued in 1983 due to the low effectiveness of the drug against Trichuris and hookworm. However, children in some rural areas are still receiving albendazole tablets. This is an intermittent distribution, without any monitoring system, of anthelmintics by researchers and community health campaigns by the Ministry of Health. This practice is not recommended as it may contribute to the emergence of anthelmintics drug resistance. Moreover, the re-infection rates of STH were reported to be high and by 6 months after complete deworming the prevalence and intensity of infections were similar to pre-treatment levels [50,51].

Orang Asli communities in Peninsular Malaysia share similar socioeconomic, environmental and health profiles. Our study provides a community-based picture of STH status among children with a poor socioeconomic, environmental and personal hygiene background. Thus, we may speculate that the findings of the present study can be generalised to rural Orang Asli children in other states. On the other hand, these results may not be generalisable to the entire Malaysian rural population as ethnic groups other than Orang Asli have a better socioeconomic and environmental situation. However, further investigations are required to confirm these conjectures.

\section{Conclusions}

This study reveals an alarmingly high prevalence of STH among Orang Asli children and this supports an urgent need to start an integrated and effective STH control programme. School-age, lack of toilets and piped water supply in the house, large family size ( $\geq 7$ members), and not washing hands before eating and after defecation were the key factors significantly associated with STH infections in the studied population. Based on these findings, implementing periodic school-based de-worming programmes, providing proper sanitation and portable safe water supply, and providing proper health education pertinent to good personal hygiene and good sanitary practices will help in reducing the prevalence and intensity of STH in these communities. In connection with the importance of community participation in the prevention and control activities, it is essential to evaluate knowledge, attitude and practices of the concerned population before attempting to introduce any change or innovation.
Competing interests

The authors have declared that no competing interests exist.

\section{Authors' contributions}

NAN was involved in all phases of the study, including data collection, data analysis, interpretation, and write-up of the manuscript; $A B$ and HMA designed and supervised the study, and revised the analysis and manuscript. AA and MAR were involved in the collection and laboratory examination of samples. All authors read and approved the final manuscript.

\section{Acknowledgements}

We gratefully acknowledge the Department of Orang Asli Development (JAKOA), Ministry of Rural and Regional Development, Kuala Lumpur, Malaysia for their cooperation during this study. We also wish to express our appreciation to the parents and their children for their voluntary participation in this study. The work presented in this paper was funded by University of Malaya Research Grants (RG439/12HTM and PS228/2010B) and University of Malaya High Impact Research Fund, HIR-MOHE (H-20001-00-E00051).

\section{Author details}

${ }^{1}$ Department of Parasitology, Faculty of Medicine, University of Malaya, 50603, Kuala Lumpur, Malaysia. ²Department of Biology, Faculty of Natural and Applied Sciences, Umaru Musa Yar'adua University, Katsina, Katsina State, Nigeria. ${ }^{3}$ Julius Centre University of Malaya, Department of Social \& Preventive Medicine, Faculty of Medicine, University of Malaya, 50603, Kuala Lumpur, Malaysia. ${ }^{4}$ Department of Parasitology, Faculty of Medicine and Health Sciences, Sana'a University, Sana'a, Yemen.

Received: 16 January 2013 Accepted: 24 January 2013

Published: 28 January 2013

\section{References}

1. Hotez PJ, Ehrenberg JP: Escalating the global fight against neglected tropical diseases through interventions in the Asia Pacific region. Adv Parasitol 2010, 72:31-53.

2. WHO: Soil-transmitted helminthiases. Eliminating soil-transmitted helminthiases as a public health problem in children: Progress report 2001-2010 and strategic plan 2011-2020. Geneva: World Health Organisation; 2012.

3. Hotez PJ, Fenwick A, Savioli L, Molyneux DH: Rescuing the bottom billion through control of neglected tropical diseases. Lancet 2009, 373:1570-1575.

4. WHO: Preventive chemotheraphy in human helminthiasis. Coordinated use of anthelminthic drugs in control interventions: A manual for health professionals and programme managers. Geneva: World Health Organisation; 2006.

5. Ahmed A, Al-Mekhlafi HM, Choy SH, Ithoi I, Al-Adhroey AH, Abdulsalam AM, Surin J: The burden of moderate-to-heavy soil-transmitted helminth infections among rural Malaysian aborigines: an urgent need for an integrated control programme. Parasit Vectors 2011, 4:242.

6. Nokes C, Grantham-McGregor SM, Sawyer A, Cooper ES, Robinson BA, Bundy DA: Moderate to heavy infections of Trichuris trichiura affect cognitive function in Jamaican school children. Parasitol 1992, 104:539-547.

7. Al-Mekhlafi HMS, Azlin M, NorAini U, Shaik A, Sa'aih A, Fatmah A, Ismail MG, Ahmad Firdaus MS, Aisah MY, Rozlida AR, Moktar N: Malnutrition and soil-transmitted helminthiasis among Orang Asli children in Selangor, Malaysia. Asia Pac J Clin Nutr 2005, 14:188-194.

8. WHO: De-worming for health and development. Report of the third global meeting of the partners for parasite control. Geneva: World Health Organisation; 2005.

9. Dreyfuss ML, Stoltzfus RJ, Shrestha JB, Pradhan EK, LeClerq SC, Khatry SK, Shrestha SR, Katz J, Albonico M, West KP Jr: Hookworms, malaria and vitamin A deficiency contribute to anemia and iron deficiency among pregnant women in the plains of Nepal. J Nutr 2000, 130:2527-2536.

10. Guyatt $\mathrm{H}$ : Do intestinal nematodes affect productivity in adulthood? Parasitol Today 2000, 16:153-158

11. Bleakley $\mathrm{H}$ : Disease and development: evidence from hookworm eradication in the American South. Quart J Econom 2007, 122:73-117.

12. Kamel M, Ghafar Y, Foda N, Khashab S: Impact of type and stage of schistosomiasis on quality of life and productivity of infected workers. J Egypt Soc Parasitol 2001, 3:153-167.

13. Conteh L, Engels T, Molyneux DH: Socioeconomic aspects of neglected tropical diseases. Lancet 2010, 375:239-247. 
14. Molyneux DH, Malecela MN: Neglected tropical diseases and the millennium development goals: why the "other diseases" matter: reality versus rhetoric. Parasit Vectors 2011, 4:234.

15. Jamaiah I, Rohela M: Prevalence of intestinal parasites among members of the public in Kuala Lumpur, Malaysia. Southeast Asian J Trop Med Public Health 2005, 36:68-71.

16. Al-Mekhlafi MS, Atiya AS, Lim YA, Mahdy AK, Ariffin WA, Abdullah HC, Surin J: An unceasing problem: soil-transmitted helminthiases in rural Malaysian communities. Southeast Asian J Trop Med Public Health 2007, 38:998-1007.

17. Norhayati M, Zainudin B, Mohammod C, Oothuman P, Azizi O, Fatmah MS: The prevalence of Trichuris, Ascaris and hookworm infection in Orang Asli children. Southeast Asian J Trop Med Public Health 1997, 28:161-168.

18. Bundy DAP, Kan SP, Rose R: Age-related prevalence, intensity and frequency distribution of gastrointestinal helminth infection in urban slum children from Kuala Lumpur, Malaysia. Trans R Soc Trop Med Hyg 1988, 82:289-294.

19. Dunn FL: Intestinal parasitism in Malayan aborigines (Orang Asli). Bull World Health Organ 1972, 46:99-113.

20. Russell PF: Nematodes in man in the straits settlements: A preliminary report. Medical J Malaysia 1928, 3:113-123.

21. Nasr NA, Al-Mekhlafi HM, Ahmed A, Roslan MA, Bulgiba A: Towards an effective control programme of soil-transmitted helminth infections among Orang Asli in rural Malaysia. Part 2: Knowledge, attitude, and practices. Parasit Vectors 2013, 6:28.

22. Cheesbrough M: Medical Laboratory Manual for Tropical Countries, Volume II. Cambridge: ELBS; 1992

23. WHO: Prevention and control of intestinal parasitic infections: prevention and control of schistosomiasis and soil-transmitted helminthiasis. Technical report series: 912. Geneva: World Health Organisation; 2002.

24. Jozefzoon L, Oostburg B: Detection of hookworm and hookworm-like larvae in human fecocultures in Suriname. Am J Trop Med Hygiene 1994, 51:501-505.

25. Bendel RB, Afifi AA: Comparison of stopping rules in forward "stepwise" regression. J Am Stat Assoc 1977, 72:46-53.

26. Norhayati M, Fatmah MS, Yusof S, Edariah AB: Intestinal parasitic infections in man: A review. Med J Malaysia 2003, 58:296-305.

27. Azian MY, Sakhone L, Hakim SL, Yusri MY, Nurulsyamzawaty Y, Zuhaizam AH, Mohd Rodi I, Maslawaty MN: Detection of helminth infections in dogs and soil contamination in rural and urban areas. Southeast Asian J Trop Med Pub Health 2008, 39:205-212.

28. Ngui R, Ishak S, Chuen CS, Mahmud R, Lim YAL: Prevalence and risk factors of intestinal parasitism in rural and remote West Malaysia. PLoS Negl Trop Dis 2011, 5:e974

29. Tomono N, Anantaphruti MT, Jongsuksuntigul P, Thongthien P, Leerapan P, Silapharatsamee $Y$, Kojima S, Looareesuwan S: Risk factors of helminthiases among schoolchildren in southern Thailand. Southeast Asian J Trop Med Public Health 2003, 34:264-268.

30. Anantaphruti MT, Waikagul J, Maipanich W, Nuamtanong S, Pubampen S: Soil-transmitted helminthiases and health behaviors among schoolchildren and community members in a west-central border area of Thailand. Southeast Asian J Trop Med Public Health 2004, 35:260-266.

31. Yap P, Du ZW, Chen R, Zhang LP, Wu FW, Wang J, Wang XZ, Zhou H, Zhou XN, Utzinger J, Steinmann P: Soil-transmitted helminth infections and physical fitness in school-aged Bulang children in southwest China: results from a cross-sectional survey. Parasit Vectors 2012, 5:50.

32. Knopp S, Mohammed KA, Speich B, Hattendorf J, Khamis IS, Khamis AN, Stothard JR, Rollinson D, Marti H, Utzinger J: Albendazole and mebendazole administered alone or in combination with ivermectin against Trichuris trichiura: A randomized controlled trial. Clin Infect Dis 2010, 51:1420-1428.

33. Norhayati M, Oothuman P, Azizi O, Fatmah MS: Efficacy of single dose albendazole on the prevalence and intensity of infection of soiltransmitted helminthes in Orang Asli children in Malaysia. Southeast Asian J Trop Med Pub Health 1998, 28:563-569.

34. Penggabean $M$, Oothuman $P$, Fatmah M: Efficacy of albendazole in the treatment of Trichuris trichuria and Giardia intestinalis infection in rural Malay communities. Medical J Malaysia 1998, 53:408-412.

35. Bethony J, Brooker S, Albonico M, Geiger SM, Loukas A, Diemert D, Hotez PJ: Soil-transmitted helminth infections: ascariasis, trichuriasis, and hookworm. Lancet 2006, 367:1521-1532.

36. Hanjeet $\mathrm{K}$, Mathias R: The efficacy of treatment with albendazole. Acta Trop 1991, 50:111-114.
37. Saathoff E, Olsen A, Sharp B, Kvalsvig JD, Appleton CC, Kleinschmidt I: Ecologic covariates of hookworm infection and re-infection in rural Kwazulu-Natal/South Africa: A geographic information system-based study. AmJTrop Med Hyg 2005, 72:384-391.

38. Nokes C, Bundy D: Does helminth infection affect mental processing and educational achievement? Parasitol Today 1994, 10:14-18.

39. Ahmed A, Al-Mekhlafi H, Azam M, Ithoi I, Al-Adhroey A, Abdulsalam A, Surin J: Soil-transmitted helminthiasis: a critical but neglected factor influencing school participation of Aboriginal children in rural Malaysia. Parasitol 2012, 139:802-808.

40. Nor Aini U, Al-Mekhlafi HM, Azlin M, Shaik A, Sa'iah A, Fatmah MS, Ismail MG, Ahmad Firdaus MS, Aisah MY, Rozlida AR, Moktar N: Serum Iron Status in Orang Asli children living in endemic areas of soil-transmitted helminthes. Asia Pac J Clin Nutr 2007, 16:724-730

41. Al-Mekhlafi HM, Surin J, Sallam AA, Abdullah AW, Mahdy MAK: Giardiasis and poor vitamin A status among aboriginal school children in rural Malaysia. AmJTrop Med Hyg 2010, 83:523-527.

42. Brooker S, Clements ACA, Bundy DAP: Global epidemiology, ecology and control of soil-transmitted helminth infections. Adv Parasitol 2006, 62:221-261.

43. Naish S, McCarthy J, Williams G: Prevalence, intensity and risk factors for soil-transmitted helminth infection in a South Indian fishing village. Acta Trop 2004, 91:177-187.

44. Luoba Al, Wenzel GP, Estambale B, Ouma JH, Alusala D, Ayah R, Mwaniki D, Magnussen $\mathrm{P}$, Friis $\mathrm{H}$ : Earth-eating and re-infection with intestinal helminths among pregnant and lactating women in western Kenya. Trop Med Int Health 2005, 10:220-227.

45. Quihui L, Valencia ME, Crompton DWT, Phillips S, Hagan P, Morales G, Diaz-Camacho SP: Role of the employment status and education of mothers in the prevalence of intestinal parasitic infections in Mexican rural schoolchildren. BMC Publ Health 2006, 6:225.

46. Belyhun Y, Medhin G, Amberbir A, Erko B, Hanlon C: Prevalence and risk factors for soil-transmitted helminths infection in mothers and their infants in Butajira, Ethiopia: A population based study. BMC Publ Health 2010, 10:21.

47. Fung $\mathrm{H}_{\mathrm{H}}$, Cairncross S: Ascariasis and handwashing. Trans $R$ Soc Trop Med Hyg 2009, 103:215-222

48. Forrester J, Scott M, Bundy D, Golden M: Clustering of Ascaris lumbricoides and Trichuris trichiura infections within households. Trans $R$ Soc Trop Med Hyg 1988, 82:282-288.

49. Anuar TS, Al-Mekhlafi HM, Ghani MK, Osman E, Yasin AM, Nordin A, Azreen SN, Salleh FM, Ghazali N, Bernadus M, Moktar N: Giardiasis among different tribes of Orang Asli in Malaysia: Highlighting the presence of other family members infected with Giardia intestinalis as a main risk factor. Int J Parasitol 2012, 42:871-880.

50. Albonico M, Bickle Q, Ramsan M, Montresor A, Savioli L, Taylor M: Efficacy of mebendazole and levamisole alone or in combination against intestinal nematode infections after repeated targeted mebendazole treatment in Zanzibar. Bull World Health Organ 2003, 81:343-352.

51. Hesham Al-Mekhlafi M, Surin J, Atiya AS, Ariffin WAW, Mahdy AKM, Abdullah HC Pattern and predictors of soil-transmitted helminth re-infection among aboriginal school children in rural peninsular Malaysia. Acta Trop 2008, 107:200-204.

doi:10.1186/1756-3305-6-27

Cite this article as: Nasr et al:: Towards an effective control programme of soil-transmitted helminth infections among Orang Asli in rural Malaysia. Part 1: Prevalence and associated key factors. Parasites \& Vectors 2013 6:27 